\title{
Investigation of Used Engine Oil Lubricating Performance Through Oil Analysis and Friction and Wear Measurements
}

\author{
A. L. Nagy $^{1}$, J. Knaup ${ }^{2}$, I. Zsoldos ${ }^{1}$ \\ ${ }^{1}$ Széchenyi István University \\ Egyetem tér 1., 9026, Gyốr, Hungary \\ E-mail: nagy.andras1@sze.hu \\ ${ }^{2}$ Audi Hungaria Zrt. \\ Audi Hungária út 1., 9027, Gyôr, Hungary
}

Abstract: Engine oil degradation during long-term engine operation is a wellresearched topic, however, the effect of biofuels and synthetic compounds is not fully understood. In order to characterise novel fuel related phenomena in an engine a basis of studies should be established with state-of-the-art engines and conventional fuels and lubricants. This study aims at describing the behaviour of used engine oils throughout their service life based on friction and wear measurements with oil samples from three identical light-duty direct injection supercharged diesel engines. Oil samples were taken from each engine every 50 hours between oil changes to determine physical properties and chemical composition. Friction and wear measurements were conducted on a high-frequency reciprocating rig. The results show strong correlation between oil service life and boron content, as well as acid number and base number. A similar correlation between coefficient of friction with used samples and boron content as well as soot content was observed. A simple model based on a polynomial fitting function was proposed to predict friction and wear from boron content, total acid number and total base number.

Keywords: engine oil degradation, friction, wear, lubrication 


\section{Introduction}

The lubricant in an engine serves multiple purposes, which demands a complex formulation in order to fulfil its function. Aside from friction and wear reduction the oil protects engine parts against corrosion and oxidation, removes third bodies from sliding pairs, transfers heat away from core engine components and helps in achieving appropriate sealing and reducing vibration.

The engine oil composes of a base oil and an additive package [1]. Modern engine oils are mostly polyalphaolefin based, which has inferior properties as a lubricant, hence a selection of additives is needed to achieve the desired function. The most common additives are anti-wear, anti-oxidant, dispersant, detergent, friction modifier, viscosity modifier, extreme pressure agent, anti-foaming agent and emulsifier compounds [2]. A certain property can be achieved through different chemical compounds, but the interaction and compatibility of these compounds with each other must be considered during the formulation of the lubricant.

An engine oil encounters elevated temperatures, high mechanical load, multiple chemically active solids and gases and foreign contaminants during its service life which can contribute to its degradation [3]. Therefore, the lubricant needs to be changed several times during the lifetime of the engine [4]. The main reason of oil degradation is oxidation through the $\mathrm{O}_{2}$ content of fresh intake air and exhaust gas. The rate of oxidation will increase with rising temperature, which can also lead to the formation of peroxides and free radicals in the engine oil, which in turn can contribute to acid and sludge formation. Oxidation can also lead to an increase in viscosity due to polymerization between the base oil molecules.

State of the art passenger car and commercial vehicle engines implement direct injection fuel systems with high injection pressures and varied injection timing strategies. Injecting fuel directly inside the combustion chamber offers a more precise control over mixture formation and the combustion process which together with charging allows for higher specific power and torque, but also increases the phenomenon of fuel transport through the piston ring package [5], [6], [7]. Fuel and fuel derivatives can contaminate the engine oil and cause further degradation mechanisms. Unburden hydrocarbons can get into the engine oil from the combustion chamber through blow-by gases. Defective injectors, bad fuel spray orientation and 
increased gaps between the piston, piston rings and cylinder wall due to wear may cause increased fuel transport into the crankcase. Fuel dilution can cause lubrication issues [8], although in normal operating conditions without any fuel line malfunction the fuel content of the engine oil should stay at a manageable level due to evaporation at higher operating temperatures [9]. However, biofuels can alter these tendencies [10].

The goal of this study is to describe the condition of the engine oil at consequent stages of use and to predict the behaviour of a specific engine oil after a given service life regarding friction and wear through chemical analysis of oil samples from three identical light-duty direct injection supercharged diesel engines.

\section{Methodology}

Three identical series production turbocharged direct injection diesel engines with a specific power of $60 \mathrm{~kW} / \mathrm{l}$ were investigated on an engine test bed. Each engine was subjected to a different test cycle with moderate to high loads and engine speeds. The engines were filled with a commercially available SAE 0 W-30 grade fully synthetic lubricant with an oil change period of 250 hours. Oil samples were taken every 50 hours for oil condition monitoring purposes and sent to oil analysis. All engines were fuelled with EN 590 compliant regular diesel fuel during the test runs.

The first test cycle (C1) is intended to simulate the conditions of real-life driving and consist of mixed loads and engine speeds. The second test cycle (C2) is designed to stress the exhaust gas recirculation system of the engine and consists of discrete steps with varying engine speeds and throttle positions. The third test cycle was designed to stress the engine to its limits and consist of differing engine speeds with wide-open throttle and half-load conditions.

A total of 43 oil samples were collected and sent to oil analysis in order to characterize the state of used engine oils. Kinematic viscosity at $40^{\circ} \mathrm{C}$ and $100^{\circ} \mathrm{C}$ were determined according to ASTM D 7279-16 [11]. Acid number and base number were determined through potentiometric titration according to ASTM D 664-11a [12] and ASTM D 2896-15 [13], respectively. Additive content was determined through inductively decoupled plasma atomic emission spectroscopy according to 
ASTM D 5185-13e1 [14]. Soot content was determined through infrared spectrometry according to DIN 51452 [15]. Wear metal content was determined through analytical ferrography. Oil samples were homogenised before analysis. A comprehensive list of measured oil properties is given in Table 1 .

Table 1. Measured properties of oil samples with their respective units

\begin{tabular}{lccc}
\hline Property type & \multicolumn{3}{c}{ Property [unit] } \\
\hline General & $\mathrm{ELh}[\mathrm{h}]$ & $\mathrm{OAh}[\mathrm{h}]$ & $\mathrm{OCI}[-]$ \\
Physical & $\mathrm{KV} 40\left[\mathrm{~mm}^{2} / \mathrm{s}\right]$ & $\mathrm{KV} 100\left[\mathrm{~mm}^{2} / \mathrm{s}\right]$ & \\
Chemical & $\mathrm{TAN}[\mathrm{mgKOH} / \mathrm{g}]$ & $\mathrm{TBN}[\mathrm{mgKOH} / \mathrm{g}]$ & \\
Contaminant & $\mathrm{ST}[\%]$ & $\mathrm{Na}[\mathrm{mg} / \mathrm{kg}]$ & $\mathrm{Si}[\mathrm{mg} / \mathrm{kg}]$ \\
Wear metal & $\mathrm{Al}[\mathrm{mg} / \mathrm{kg}]$ & $\mathrm{Cr}[\mathrm{mg} / \mathrm{kg}]$ & $\mathrm{Cu}[\mathrm{mg} / \mathrm{kg}]$ \\
& $\mathrm{Fe}[\mathrm{mg} / \mathrm{kg}]$ & & \\
Additive & $\mathrm{Ca}[\mathrm{mg} / \mathrm{kg}]$ & $\mathrm{Mg}[\mathrm{mg} / \mathrm{kg}]$ & $\mathrm{P}[\mathrm{mg} / \mathrm{kg}]$ \\
& $\mathrm{Zn}[\mathrm{mg} / \mathrm{kg}]$ & $\mathrm{S}[\mathrm{mg} / \mathrm{kg}]$ & $\mathrm{B}[\mathrm{mg} / \mathrm{kg}]$ \\
\hline
\end{tabular}

Selected oil samples were subjected to friction and wear measurements on a high frequency reciprocating rig in order to determine their lubricating performance. Sample selection was based on oil service life, since not all analysed oils were available for friction testing. To have a representation of in-engine oil degradation a complete series of samples were chosen from each test cycle, which corresponds to 1 sample of 50,100,150, 200 and 250 hours oil service life from the same oil charge of each engine. A ball-on-disc model system was utilized with a steel sliding pair for the measurements. Each sample was tested under the same circumstances in two consecutive measurements. To minimize measurement error and maximize reproducibility the testing of the aged oil samples was carried out according to the ISO 19291:2016 [16] standard. Mechanical load, stroke, speed, test duration and other boundary conditions of the measurements are given in Table 2 .

Ball and disc test specimens are supplied by Optimol Instruments with material properties and dimensions given in Table 3 . In addition to the registered coefficient of 
Table 2. Parameters of the load set used for friction and wear experiments

\begin{tabular}{lclc}
\hline Parameter & Value & Parameter & Value \\
\hline Lubricant volume $[\mathrm{ml}]$ & 0.3 & Run-in Load $[\mathrm{N}]$ & 50 \\
Stroke length $[\mathrm{mm}]$ & 1.0 & Run-in Time $[\mathrm{s}]$ & 30 \\
Frequency $[\mathrm{Hz}]$ & 50 & Normal Load $[\mathrm{N}]$ & 300 \\
Specimen Temperature $\left[{ }^{\circ} \mathrm{C}\right]$ & 50 & Total Test Time $[\mathrm{s}]$ & 7230 \\
\hline
\end{tabular}

friction (COF) curves the averaged wear scar diameter (AWSD) of each ball specimen was determined through optical microscopy as an average of two perpendicular diameter measurements. Mean COF values were determined as an arithmetic mean of the friction curve after the run-in period.

Table 3. Properties of the ball and disc specimen used for friction and wear experiments

\begin{tabular}{ccccc}
\hline Specimen & Size [mm] & Material & $\boldsymbol{R}_{\boldsymbol{a}}[\mu \mathrm{m}]$ & HRC [-] \\
\hline Ball & $\varnothing 10$ & $100 \mathrm{Cr} 6$ & $0.02 \pm 0.001$ & $61.5 \pm 1$ \\
Disc & $\varnothing 24 \times 7.9$ & $100 \mathrm{Cr} 6$ & $0.047 \pm 0.003$ & 62 \\
\hline
\end{tabular}

A linear correlation analysis according to Pearson was carried out on the data in order to assess the significance of measured oil properties in relation to the condition and lubricating performance of the oil samples. Oil properties listed in Table 1 were correlated to service life (OAh). Subsequently, the properties of the oil samples subjected to friction and wear measurements were correlated to the mean coefficient of friction and the mean averaged wear scar diameter. The calculated correlation coefficients or $r$-values lie in the range of $[-1,1]$. A strong linear relationship is characterized by an $r$-value close to $|1|$, whereas an $r$-value of 0 suggests no linear relationship between the variables. The p-value determines if the $r$-value is significantly different from 0 . A p-value less than or equal to the significance level 
signifies that the correlation is different from 0 . A level of significance of 0.05 was chosen for the evaluation of the correlation coefficients based on the corresponding $p$-values. Any oil property with a corresponding $p$-value greater than the level of significance was considered as non-determinate for this study.

\section{Results}

A correlation analysis of measured oil properties of all oil samples in relation to their service life is shown on Figure 1.

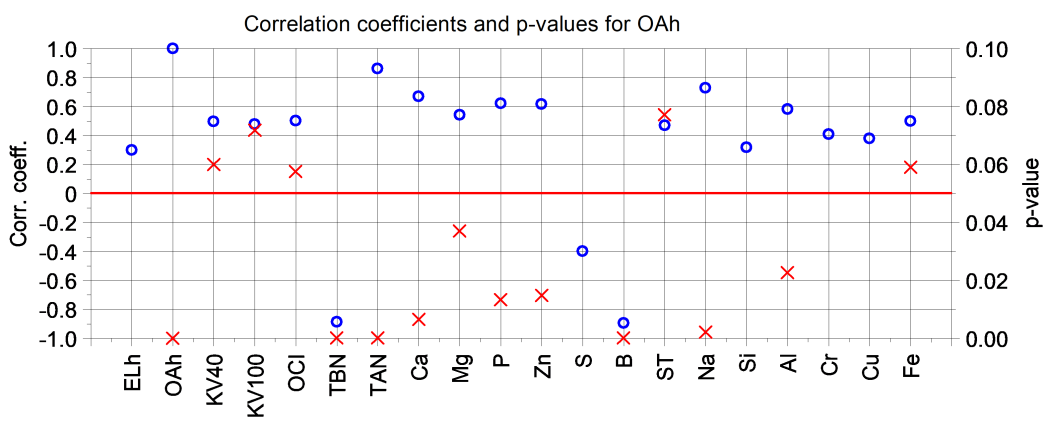

Figure 1. Correlation of measured values to oil service life (OAh); blue circles represent correlation coefficients, red crosses represent $p$-values, red line represents level of significance $(p=0.05)$

It suggests that the main indicators of engine oil fitness are TBN, TAN and boron quantity (B) in the oil, signified by low $p$-values and relatively high absolute correlation coefficients $(\geq 0.8)$. A detailed analysis of these values shows a coherent decrease of TBN and boron content as well as a steady increase of TAN with service life of measured samples regardless the test cycle (Fig. 2). In contrast to this behaviour there is noticeable separation in values of the kinematic viscosity of samples from different test cycles. These results are in-line with the expectations, based on the work of other researchers. 

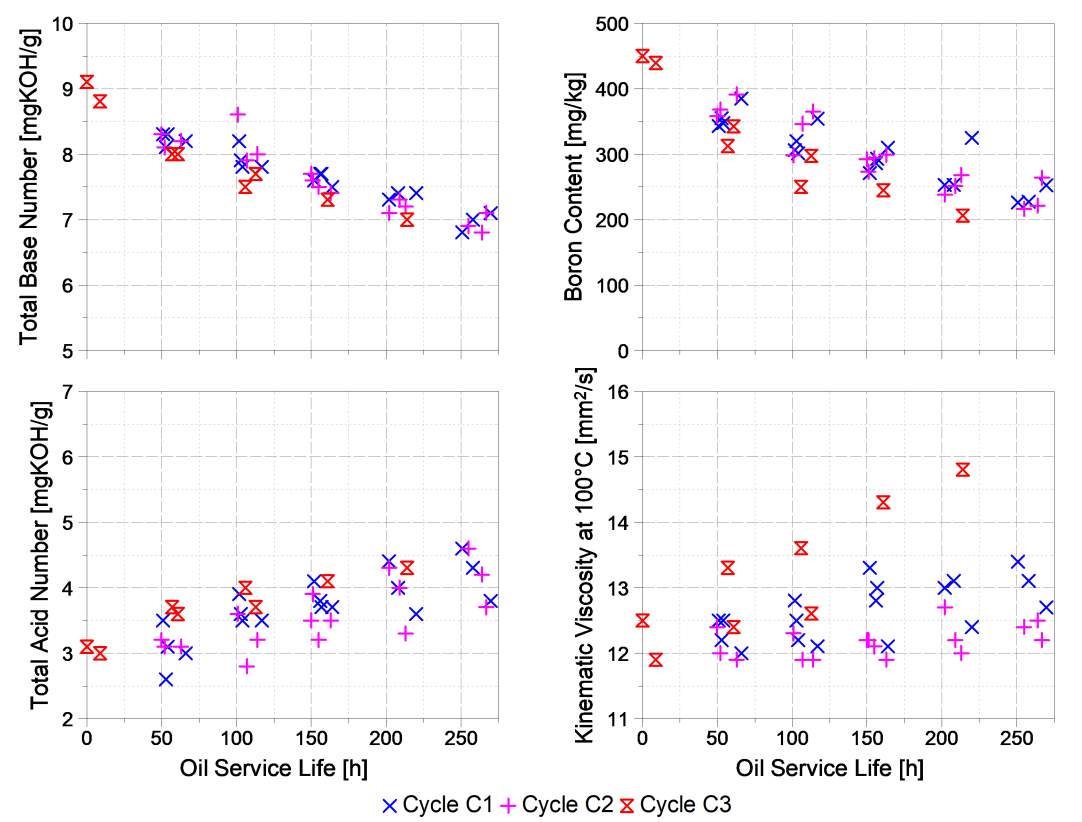

Figure 2. Measured TAN, TBN, boron content and kinematic viscosity at $100{ }^{\circ} \mathrm{C}$ with different oil samples

A mean value from the coefficient of friction curve as well as the averaged wear scar diameter of each measurement was calculated and correlated to the values from the lubricant analysis. The analysis shows a strong correlation between the boron content, soot content and TBN of the samples to the mean coefficient of friction during friction and wear testing (Fig. 3). As for the amount of wear a similar trend can be observed. Boron content and TBN show a remarkable correlation alongside with TAN. These findings seem to be in accordance with the results of used oil analysis in relation to service life.

To determine the relation between said properties the COF and AWSD values of 

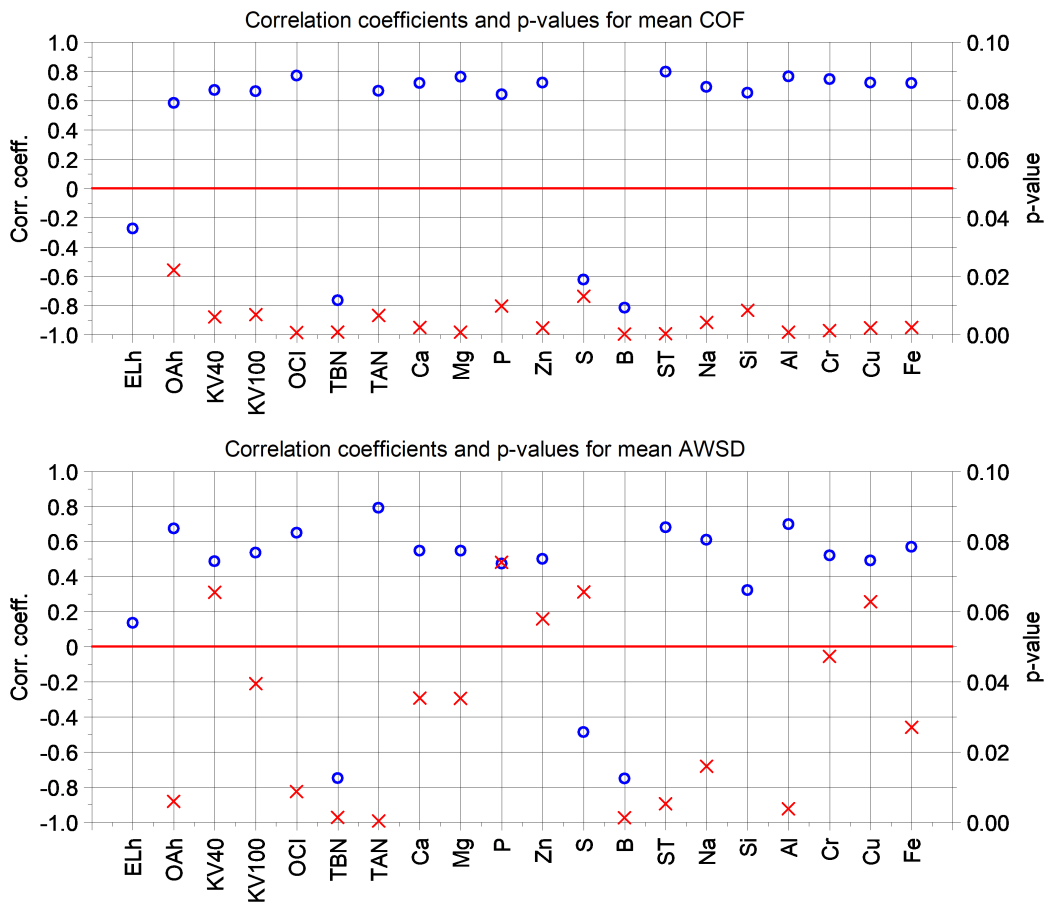

Figure 3. Correlation of measured values to mean COF (upper) and mean AWSD (lower); blue circles represent correlation coefficients, red crosses represent p-values, red line represents level of significance $(p=0.05)$

individual samples were plotted against boron content, soot content, TAN and TBN respectively (Fig. 4). Apart from COF and soot content, the relation between values appears to be linear. Although it should be noted, that the correlation between the measured coefficient of friction and oil condition is the most apparent on the COF vs. soot content plot.

Based on the presented data, the boron content of the sample together with another 

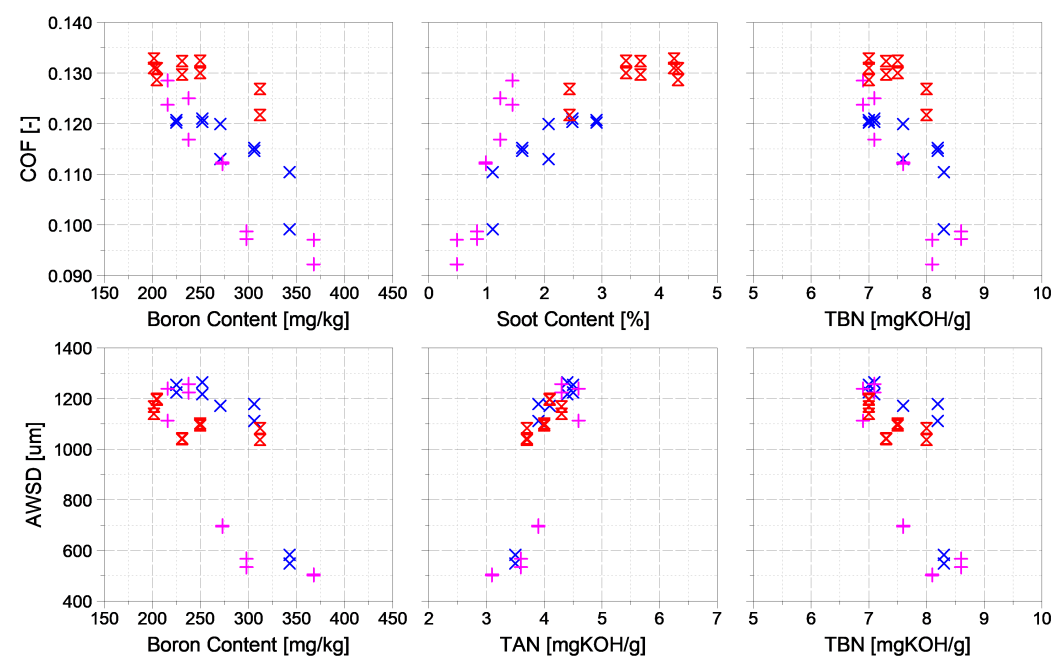

$\times$ Cycle C1 + Cycle C2 \& Cycle C3

Figure 4. Graphic representation of the relation between used engine oil properties and their performance during friction and wear testing

independent property with significant correlation could be used to describe the fitness of the lubricant in terms of friction reduction and wear protection. A second order polynomial function was found to describe the dependence of $\mathrm{COF}$ values from boron and soot content:

$$
f(x, y)=p_{0}+p_{1} \cdot x+p_{2} \cdot y+p_{3} \cdot x^{2}+p_{4} \cdot x \cdot y+p_{5} \cdot y^{2}
$$

where $f(x, y)$ represents the coefficient of friction, $x$ represents boron content and $y$ represents soot content. This with the appropriate coefficients yields an adjusted $\mathrm{R}$-value of 0.9076 and a root-mean-square error (RMSE) of 0.0036 . The repeatability of the used friction measurement procedure is 0.012 according to the standard. This means that the proposed function could be successfully used to determine the COF 
value from the measured boron and soot content of the sample. In the case of averaged wear scar diameter results the best achievable fit yielded from a similar function, with $f(x, y)$ representing AWSD, $x$ representing TAN and $y$ representing boron content. The best fitting second order polynomial function results in an adjusted R-value of 0.6659 and a RMSE of $157.136 \mu \mathrm{m}$, which is far greater than the measurement repeatability of around $70 \mu \mathrm{m}$, however lies below the border of reproducibility of around $230 \mu \mathrm{m}$.

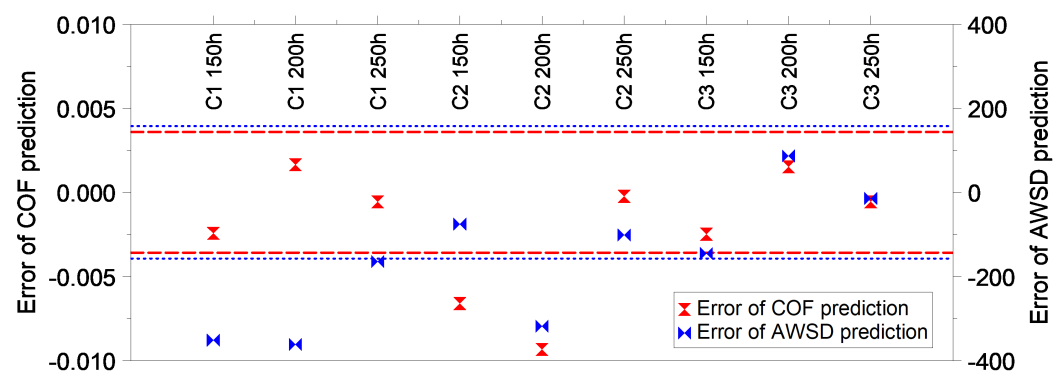

Figure 5. Absolute error of prediction for COF and AWSD with validation dataset; dashed lines represent \pm RMSE of the COF prediction model while dotted line represent the same for the AWSD prediction model

A validation dataset consisting of boron, soot and TAN values as well as measured values of COF and AWSD of selected samples was utilized in order to evaluate the fitness of the polynomial models. One samples from each test cycle (C1, C2 and C3) at 150, 200 and 250 hours service life was included in the validation dataset. The absolute difference between predicted and measured COF and AWSD values at the validation data points are depicted on Fig. 5. In the case of the COF model for 7 out of 9 predictions the error is lower than the RMSE of the fit, which can be considered a good accuracy. The AWSD model shows a worse accuracy with only 5 predictions out of 9 with an error lying under the RMSE of the fit.

Due to confidentiality the author will not disclose the coefficients of the polynomial functions. 


\section{Discussion}

The presented results presume a significant correlation between the TAN, TBN and boron content of a used engine oil and its service life. The acid number is used to measure the concentration of acidic species present in the engine oil. Lean oil has an initial acidity which will increase during service due to acid formation as a result of oxidation and the presence of acidic compounds formed during combustion. The base number measures the alkaline reserve of the lubricant which serves as a neutralizing agent to hinder the effect of weak acids. Therefore the initial base number of a lean oil will decrease during the service life [17]. Boron esters are used in modern formulations as an antioxidant additive or as replacement to ZDDP. Boron can also be used as a solid lubricant nano-additive to successfully reduce friction and wear in a sliding pair as discussed in [18], [19], [20] and [21]. In both cases the initial boron content of the lubricant will decrease with time as experienced. This phenomenon takes place due to degrading chemical reactions and boundary layer formation, which reduce the amount of boron additives in the oil. Hence, the presented results are in accordance with the scientific literature.

The conducted correlation analysis assumed a linear correlation between the investigated properties and service life, as well as coefficient of friction and averaged wear scar diameter. This assumption disregards the possibility of non-linear correlation, which can explain why only a weak fit was achievable with the wear scar diameter. Taking only linear correlations into account was a decision in favour of simplicity, as non-linear behaviour would demand finer sampling of the used oils which was not in the scope of this study. Further experimentation should be considered regarding the dependence of oil properties from the test cycle. Treating this factor as an inherent property of the dataset can introduce an error in the model. A detailed study with real-life driving conditions conducted on a diverse vehicle fleet would be necessary to address this flaw.

It should also be noted that the models presented in this study are only applicable in the case of boron containing engine lubricants, and should not be applied without further consideration to arbitrary engine oils or other lubricants. 


\section{Conclusion}

In order to describe the friction and wear behaviour of used engine oils a series of measurements was conducted on a high frequency reciprocating rig with oil samples from three identical light-duty series production diesel engines. Each engine was subjected to a different test cycle aiming at simulating different use cases. Oil samples were taken every 50 hours between oil changes and analysed in a laboratory. The results of oil analysis and friction and wear testing showed that a strong correlation exists between oil service life and TAN, TBN and boron content of the sample. These findings are in accordance with the expectations, based on the work of other authors. This correlation was found to be present in connection with the coefficient of friction and average wear scar diameter values as well, although with somewhat lower significance. Based on these findings a simple polynomial fitting model was proposed to predict the COF and AWSD values of a given oil sample without conducting the friction and wear experiments. It should be noted that only linear correlation between oil properties and measured COF and AWSD values was considered, disregarding the possibility of non-linearity between the investigated values. Since boron is not present in the base oil, the presented model approach is only applicable to engine oils containing boron additives.

\section{Acknowledgement}

The publishing of this paper was supported by EFOP-3.6.1-16-2016-00017 Internationalization, initiatives to establish a new source of researchers and graduates, and development of knowledge and technological transfer as instruments of intelligent specializations at Szechenyi University.

\section{References}

[1] M. Torbacke, A. Kassman Rudolphi, E. Kassfeldt, Lubricants: Introduction to Properties and Performance, 1st Edition, Wiley, Chichester, 2014.

[2] L. R. Rudnick, Lubricant Additives Chemistry and Application, 2nd Edition, CRC Press Inc, Boca Raton, FL, USA, 2009. 
[3] A. Toms, L. Toms, Oil analysis and condition monitoring, in: R. M. Mortier, M. F. Fox, S. Orszulik (Eds.), Chemistry and Technology of Lubricants, 3rd Edition, Springer Netherlands, Dordrecht, 2010, pp. 459-495.

[4] P. Lacey, S. Gunsel, M. Ferner, M. Pozebanchuk, A. Alim, Effect of oil drain interval on crankcase lubricant quality, SAE Technical Papersdoi:10.4271/ 2003-01-1957.

[5] T. Sagawa, H. Fujimoto, K. Nakamura, Study of fuel dilution in direct-injection and multipoint injection gasoline engines, in: SAE Technical Paper, SAE International, 2002, pp. 1107-1116. doi:10.4271/2002-01-1647.

[6] T. Hu, H. Teng, X. Luo, X. Chen, Impact of Fuel Injection on Dilution of Engine Crankcase Oil for Turbocharged Gasoline Direct-Injection Engines, SAE Int. J. Engines 8 (2015) pp. 1107-1116. doi:10.4271/2015-01-0967.

[7] P. J. Shayler, L. D. Winborn, A. Scarisbrick, Fuel transport to the crankcase, oil dilution and he return with breather flow during the cold operation of a si engine, in: SAE Technical Paper, SAE International, 2000, pp. 1107-1116. doi:10.4271/2000-01-1235.

[8] S. Watson, V. Wong, The effects of fuel dilution with biodiesel and low sulfur diesel on lubricant acidity, oxidation and corrosion: A bench scale study with cj-4 and ci-4+ lubricants, in: STLE/ASME 2008 International Joint Tribology Conference, ASME, Miami, 2008, pp. 233-235. doi:10.1115/ IJTC2008-71221.

[9] M. Hakeem, J. Anderson, G. Surnilla, S. S. Yamada, Characterization and speciation of fuel oil dilution in gasoline direct injection (di) engines, in: ASME 2015 Internal Combustion Engine Division Fall Technical Conference, ASME, Houston, Texas, USA, 2015. doi:10.1115/ICEF2015-1072.

[10] X. He, A. Williams, E. Christensen, J. Burton, R. McCormick, Biodiesel impact on engine lubricant dilution during active regeneration of aftertreatment systems, SAE Int. J. Fuels Lubr. 4 (2011) pp. 158-178. doi:10.4271/ 2011-01-2396. 
[11] ASTM D7279-16, Standard Test Method for Kinematic Viscosity of Transparent and Opaque Liquids by Automated Houillon Viscometer, Standard, ASTM International, West Conshohocken, PA, USA (2016). doi:10.1520/D7279-16.

[12] ASTM D664-11a, Standard Test Method for Acid Number of Petroleum Products by Potentiometric Titration, Standard, ASTM International, West Conshohocken, PA, USA (2011). doi:10.1520/D0664-11A.

[13] ASTM D2896-15, Standard Test Method for Base Number of Petroleum Products by Potentiometric Perchloric Acid Titration, Standard, ASTM International, West Conshohocken, PA, USA (2015), doi:10.1520/D2896-15.

[14] ASTM D5185-13e1, Standard Test Method for Multielement Determination of Used and Unused Lubricating Oils and Base Oils by Inductively Coupled Plasma Atomic Emission Spectrometry, Standard, ASTM International, West Conshohocken, PA, USA (2013). doi:10.1520/D5185-13E01.

[15] DIN 51452, Testing of lubricants; determination of the soot content in used Diesel engine oils; infrared spectrometry, Standard, Deutsches Institut für Normung e. V., Berlin, Germany (1994).

[16] ISO 19291:2016, Lubricants - Determination of tribological quantities for oils and greases - Tribological test in the translatory oscillation apparatus, Standard, International Organization for Standardization, Geneva, Switzerland (2016).

[17] D. J. Smolenski, S. E. Schwartz, Automotive engine-oil condition monitoring, in: E. R. Booser (Ed.), CRC Handbook of Lubrication and Tribology Volume III Monitoring, Materials, Synthetic Lubricants, and Applications, CRC Press, Inc, New York, 1994, pp. 17-32.

[18] H. Baş, Y. E. Karabacak, Investigation of the effects of boron additives on the performance of engine oil, Tribology Transactions 57 (4) (2014) pp. 740-748. doi:10.1080/10402004.2014.909549.

[19] J. Sahu, K. Panda, B. Gupta, N. Kumar, P. Manojkumar, M. Kamruddin, Enhanced tribo-chemical properties of oxygen functionalized mechanically exfoliated hexagonal boron nitride nanolubricant additives, Materials Chemistry and 
Physics 207 (2018) pp. 412-422. doi:10.1016/j.matchemphys. 2017. 12.050 .

[20] Q. Wan, Y. Jin, P. Sun, Y. Ding, Tribological behaviour of a lubricant oil containing boron nitride nanoparticles, Procedia Engineering 102 (2015) pp. 1038 - 1045. doi:10.1016/j.proeng.2015.01.226.

[21] L. Wang, H. Wu, D. Zhang, G. Dong, X. Xu, Y. Xie, Synthesis of a novel borate ester containing a phenylboronic group and its tribological properties as an additive in pao 6 base oil, Tribology International 121 (2018) pp. 21-19. doi:10.1016/j.triboint.2018.01.033. 